\title{
Regulation of splicing at an intermediate step in the formation of the spliceosome
}

\author{
Josep Vilardell and Jonathan R. Warner ${ }^{1}$ \\ Department of Cell Biology, Albert Einstein College of Medicine, Bronx, New York 10461 USA
}

\begin{abstract}
In vivo experiments have demonstrated that the ribosomal protein $\mathrm{L} 32$ of Saccharomyces cerevisiae brings about the inhibition of splicing of the transcript of its own gene through an RNA structure comprised largely of the first exon. We now show that L32, itself, binds specifically to this RNA. Splicing of the RPL32 transcript in vitro is blocked by the presence of L32. Furthermore, addition of the 75-nucleotide RNA representing the $5^{\prime}$ end of the RPL32 transcript stimulates specifically the splicing of the RPL32 substrate, presumably by competing for L32 present in the extract. Use of RNAs carrying mutations shown to abolish the regulation of splicing, either as substrates or as competitors, confirmed that the in vitro reaction is a faithful representation of the situation in vivo. We conclude that the regulation of splicing occurs through the specific binding of L32 to an RNA structure within the first 75 nucleotides of the RPL32 transcript. The RPL32 substrate, bound to L32, forms a complex with U1 snRNP, the first step in spliceosome assembly. The presence of $L 32$ prevents the ATP-dependent association of the U2 snRNP necessary to form a complete spliceosome.
\end{abstract}

[Key Words: RNA structure; ribosome protein; yeast; Ul snRNP; spliceosome]

Received October 12, 1993; revised version accepted November 29, 1993.

It is now clear that regulated splicing is a major element of the control of gene expression in eukaryotes. Such regulation occurs by a number of mechanisms (for review, see Smith et al. 1989; Nadal-Ginard et al. 1991; McKeown 1992; Rio 1992). The widely studied sex determination pathway of Drosophila melanogaster uses at least two (for review, see Baker 1989). The sex lethal protein (Sxl) competes with the general splicing factor $\mathrm{U} 2$ accessory factor, (U2AF), for binding to a sequence between the lariat site and the $3^{\prime}$ acceptor site in a constitutively spliced second intron of the $S x l$ transcript (Valcarcel et al. 1993) and probably of the tra transcript. The prevention of those splicing events each leads to the avoidance of a termination codon and to the female-specific production of the $s x l$ and the tra proteins. The tra protein and the constitutive tra-2 protein bind to an exon of the $d s x$ transcript serving as an enhancer for the formation of a splicing complex at an unfavorable upstream 3' site (Tian and Maniatis 1992, 1993). These provide examples of both positive and negative regulation of splicing based on the binding of specific proteins.

Tissue-specific splicing can also be regulated in a positive or negative way. The splice leading to the P-element transposase of Drosophila is restricted to the germline cells because somatic cells contain proteins that bind to the $5^{\prime}$ exon, leading to the formation of a nonproductive splicing complex at a pseudo- $5^{\prime}$ splice site (Siebel et al. 1992). In Saccharomyces cerevisiae, Mer2p,

\footnotetext{
${ }^{1}$ Corresponding author.
}

a protein essential for meiosis, is produced only in the presence of Merlp, which helps the MER2 transcript to associate with the splicing apparatus (Nandabalan et al. 1993). In other cases, the relative concentration of general splicing factors seems to determine which alternative 3' splice sites will be selected (Ge and Manley 1990; Krainer et al. 1990).

Finally, the regulation of splicing can modulate the amount of a gene product. In $S$. cerevisiae, ribosomal protein L32 appears to control its own synthesis through a feedback inhibition of the splicing of the RPL32 transcript (Dabeva et al. 1986). The synthesis of ribosomes requires an equimolar amount of the $>75$ ribosomal proteins. The fact that most ribosomal protein genes contain an intron (Woolford 1989), otherwise rare in yeast genes, suggested that this might be a general mechanism for maintaining the balance of ribosomal proteins.

The regulation of splicing of the RPL32 transcript is mediated by sequences including the first exon and the first few nucleotides of the intron. Sequence comparison between the genes of $S$. cerevisiae and Kluyveromyces lactis, computer analysis of RNA folding, and the effects of mutations on the regulation of splicing in vivo led us to propose a model of the RNA secondary structure with which L32 could interact (Fig. 1A). The $5^{\prime}$ splice site is within a stem region of this structure, suggesting that the binding of L32 would prevent the interaction of U1 RNA with the RPL32 transcript (Eng and Warner 1991).

We have now carried out an in vitro analysis of this regulation of splicing. We find that purified L 32 , in the 


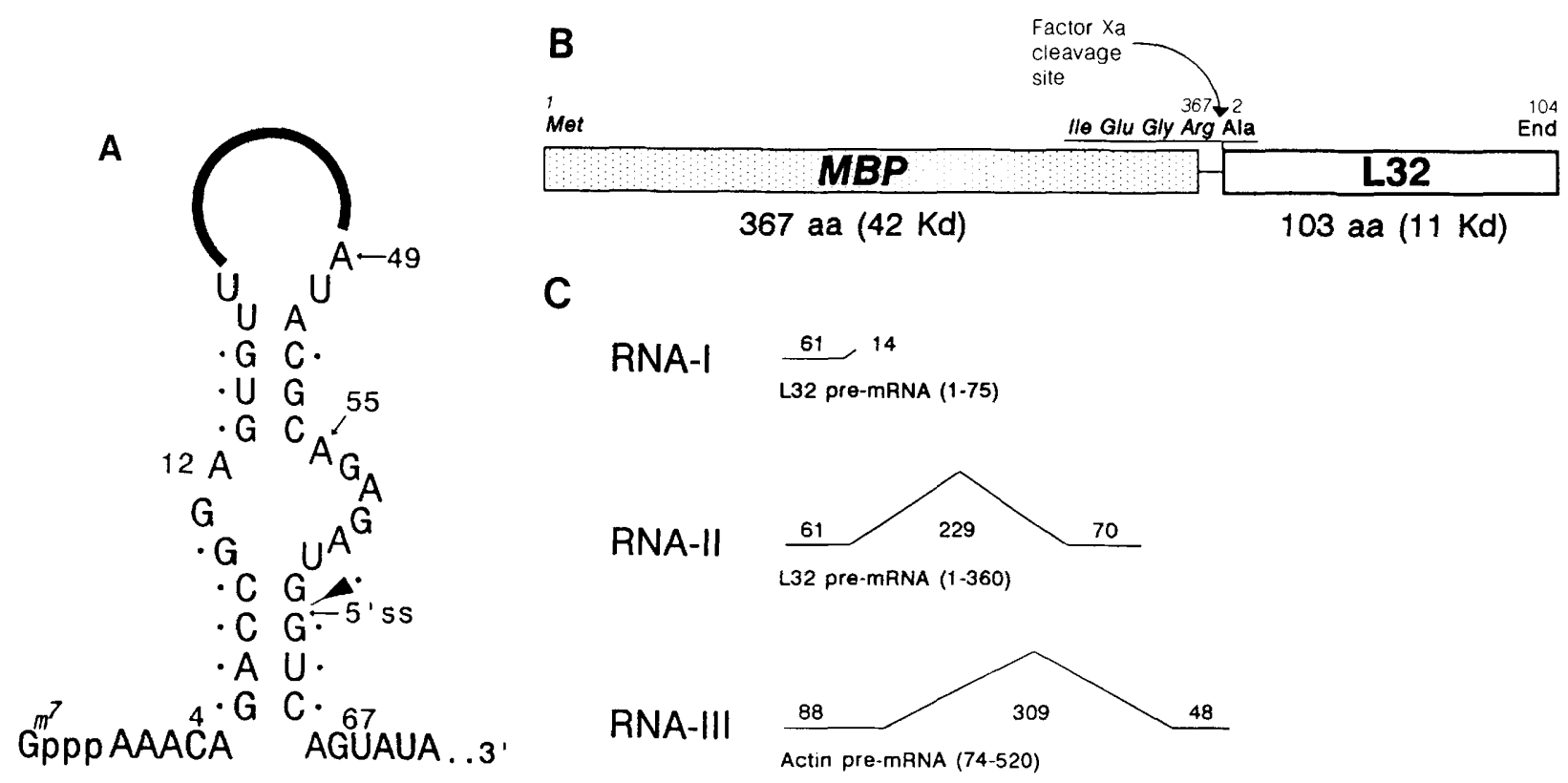

Figure 1. (A) Proposed secondary structure of the first 70 nucleotides of the RPL32 transcript (Eng and Warner 1991). The region between nucleotides 18 and 48 appears not to be involved in the regulation of splicing and is shown as a loop. Dots show those mutations that abolish the regulation of splicing. Positions 62-64 were tested only for MBP:L32 binding (see Fig. 3). The position of an AAG insertion is indicated by an arrowhead. $(B)$ Scheme of the MBP:L32 protein. $(C)$ RNA probes used in the in vitro experiments. Numbers in parentheses indicate the pre-mRNA sequences contained in the probe, referred to the start of transcription (Dabeva et al. 1986).

form of a fusion with the maltose-binding protein of Escherichia coli (MBP:L32), binds specifically to a transcript containing the first 75 nucleotides of the RPL32 gene. The splicing of an RPL32 transcript in a cell extract is detectable but inefficient. It is abolished specifically by the addition of MBP:L32, and it is enhanced specifically by addition of the RNA fragment that binds L32, presumably by titrating the L32 protein present in the extract. Surprisingly, we find that a substrate bound to MBP:L32 can undergo the initial step of spliceosome assembly, the association with U1 small nuclear ribonucleoprotein (snRNP). L32 blocks subsequent assembly steps, namely the ATP dependent interaction with $U 2$ snRNP.

\section{Results}

\section{$L 32$ can be replaced in vivo by a MBP:L32 fusion} protein

To study the regulation of splicing of the RPL32 transcript in vitro, it was essential to have a supply of L32 in an active form. However, purification of a ribosomal protein from ribosomes entails extensive denaturation, and there is no assay for the return of the protein to the proper conformation at the end of the process. Attempts to synthesize L32 in E. coli yielded only an insoluble product; therefore, a gene was constructed that encodes a fusion between the MBP from $E$. coli (Maina et al. 1988) and L32 (MBP:L32; Fig. 1B). The MBP:L32 obtained from $E$. coli is highly soluble and can be readily purified.
To ask whether MBP:L32 has biological activity, its gene, driven by the GAL10 promoter, was inserted into a multicopy plasmid that was introduced into a diploid yeast strain in which one RPL32 gene has been disrupted by the HIS3 marker (JVl; see Materials and methods). Sporulation yielded haploid cells (JV2) that were His ${ }^{+}$ and dependent on galactose. Analysis of ribosomal proteins in those cells showed that the entire MBP:L32 is incorporated into the ribosomes, apparently in equimolar amounts with the other ribosomal proteins (B-I. Li, J. Vilardell, and J.R. Warner, in prep.). No free MBP was detected in Western blot analysis of protein extracts of strain JV2. Furthermore, overproduction of the MBP:L32 in a wild-type strain leads to an accumulation of the RPL32 unspliced transcript (Fig. 2A, lanes 2,3). The degree of inhibition is comparable to that observed when L32 itself is overproduced (Eng and Warner 1991). It is interesting that the intact MBP:L32, of $53 \mathrm{kD}$, can substitute for ribosomal protein $\mathrm{L} 32$, of $11 \mathrm{kD}$, both in the formation of a ribosome and in the regulation of splicing of the RPL32 transcript.

The MBP:L32 protein binds specifically the RPL32 transcript

Genetic analysis showed that the first 75 nucleotides of the RPL32 transcript, comprising the first exon and 14 bases of the intron, are sufficient for the regulation of splicing. Comparative sequence analysis and the phenotype of numerous site-directed mutations suggested that 


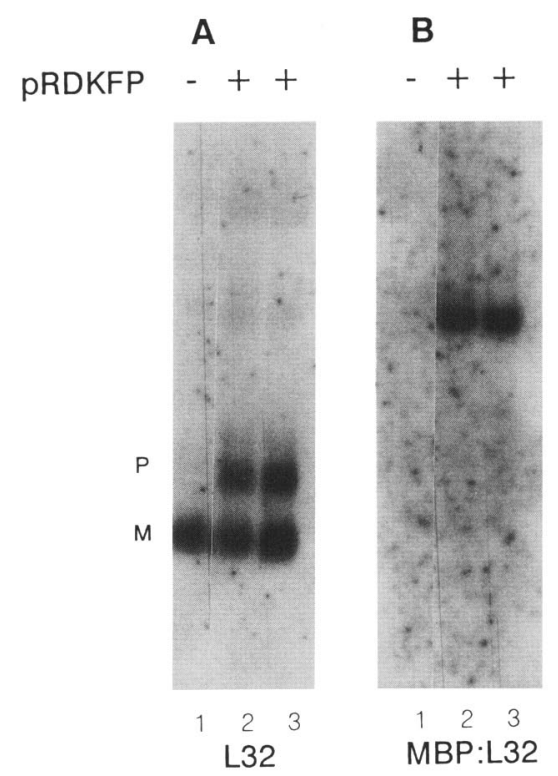

Figure 2. Northern analysis of total RNA extracted from yeast cells (strain W303) expressing the MBP:L32 protein. (Lanes 1) RNA from wild-type W303 strain; (lanes 2,3) RNA from two independent transformants of plasmid pRDKFP carrying the MBP:L32 gene. In each lane, $5 \mu \mathrm{g}$ of total RNA was analyzed (Eng and Warner 1991). (A) Filter probed with an oligonucleotide complementary to nucleotides +3 to -19 in the first exon of RPL32. Positions of the precursor unspliced RNA (P) and the mature spliced RNA (M) are indicated. (B) The same filter hybridized with an oligonucleotide complementary to the malE gene from E. coli, for specific detection of the $M B P: L 32$ transcript.

the region can fold in a stem-loop structure as depicted in Figure 1A (Eng and Warner 1991). Using the in vitro transcripts shown in Figure 1C, we ask whether the MBP:L32 protein can bind to this regulatory sequence.

A radioactive copy of this RNA molecule (RNA-I) was subjected to bandshift analysis with purified MBP:L32 (Fig. 3). It is evident (lane 2) that a strong interaction occurs between the two. The binding is competed both by an excess of unlabeled RNA-I (lane 3) and by a longer transcript of RPL32 that includes the entire intron and part of the second exon (RNA-II; lane 4). This result shows that a substrate for splicing can also fold into a conformation that binds L32. RNA molecules derived from other genes, ACT1 (lane 5) or RPS10A (lane 12), do not compete. More important, transcripts of several mutant forms of RPL32, not subject to the regulation of splicing by L32 in vivo (Eng and Warner 1991), do not compete for binding (lanes 6-8). This is true of mutations that weaken either the lower stem $\left(\mathrm{C}_{9} \rightarrow \mathrm{U}\right.$; lane 6) or the upper stem $\left(U_{14} \rightarrow A_{\text {; lane }} 7\right)$.

The in vitro assay enabled us to test the effect of mutations that were inaccessible to the in vivo assay, such as those at the $5^{\prime}$ splice site that prevent splicing. $\mathrm{Mu}$ tations $\mathrm{G}_{61} \rightarrow \mathrm{A}$ or $\mathrm{G}_{62} \rightarrow \mathrm{A}$ abolish binding of the MBP:L32 (lanes 9,10); $U_{63} \rightarrow C$ weakens it substantially (lane 11). These results strengthen the experimental ba- sis of the structure proposed previously (see Fig. 1A) (Eng and Warner 1991) and suggest that the regulation of splicing is attributable directly to the binding of L32 to the structure diagramed in Figure 1A.

\section{Binding of MBP:L32 inhibits splicing in vitro}

The model of autoregulation specifies that binding of L32 prevents the splicing of the RPL32 transcript. This prediction was tested by assaying the effect of MBP:L32 on splicing in vitro. As shown in Figure 4A, splicing of the ACT1 transcript is efficient (lane 3 ) and is not affected by the presence of MBP:L32 in the extracts (lane 4). In contrast, the RPL32 transcript is spliced poorly in vitro under the same conditions (lane 8). Furthermore, addition of MBP:L32 (lane 9), but not of MBP alone (lane $10 \mid$, significantly inhibits its splicing. There is a clear relationship between the amount of added MBP:L32 and the inhibition of splicing (Fig. 5A).

The model predicts that the MBP:L32 would not affect the splicing of the mutant transcripts of RPL32 to which it does not bind. This was confirmed in the case of the mutant $C_{9} \rightarrow U$ (Fig. 4B). Its transcript is spliced effectively in vitro (lane 3 ), even in the presence of $2 \mu \mathrm{g}$ of MBP:L32 in the reaction (lane 4). The mutant $U_{14} \rightarrow A$ has been tested with identical results (data not shown).

One explanation of the low splicing efficiency of the wild-type $R P L 32$ transcript is that the $\mathrm{L} 32$ protein could be present in the splicing extracts. If so, it should be feasible to increase the splicing specifically of an RPL32 transcript by removing L32. To this end, cold RNA-I, the first 75 nucleotides of the RPL32 transcript, was added to the splicing extract before the substrate. Because RNA-I has only the $5^{\prime}$ splice site, it will not enter into the splicing pathway (Ruby and Abelson 1988; Séraphin and Rosbash 1989). Yet it binds L32 (see Fig. 3, lane 2); thus, any

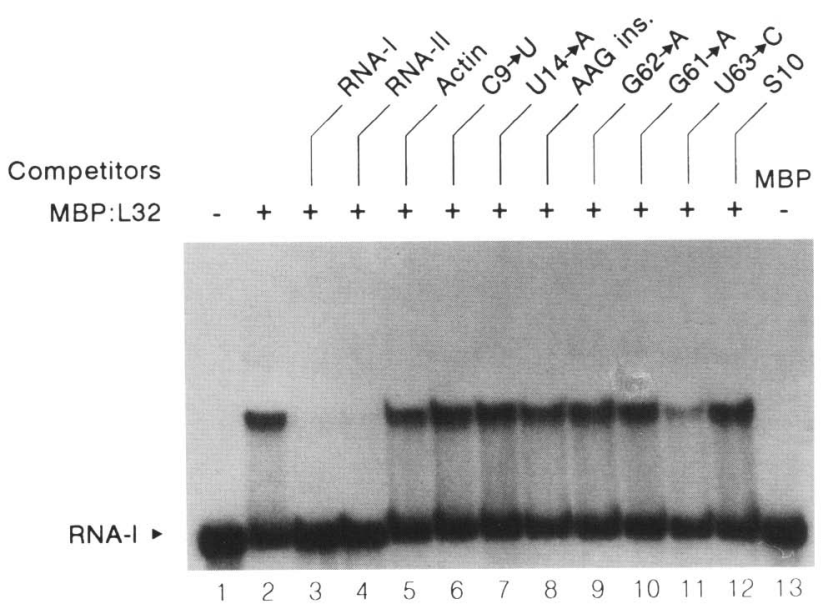

Figure 3. Mobility-shift analysis. ${ }^{32} \mathrm{P}$-Labeled RNA-I was mixed with tRNA and tested for binding in the presence of the following components: (Lane 1) blank; (lane 2) MBP:L32; (lanes 3-12) MBP:L32 and the indicated competitors in 50- to 100-fold molar excess; (lane 13) MBP alone. 

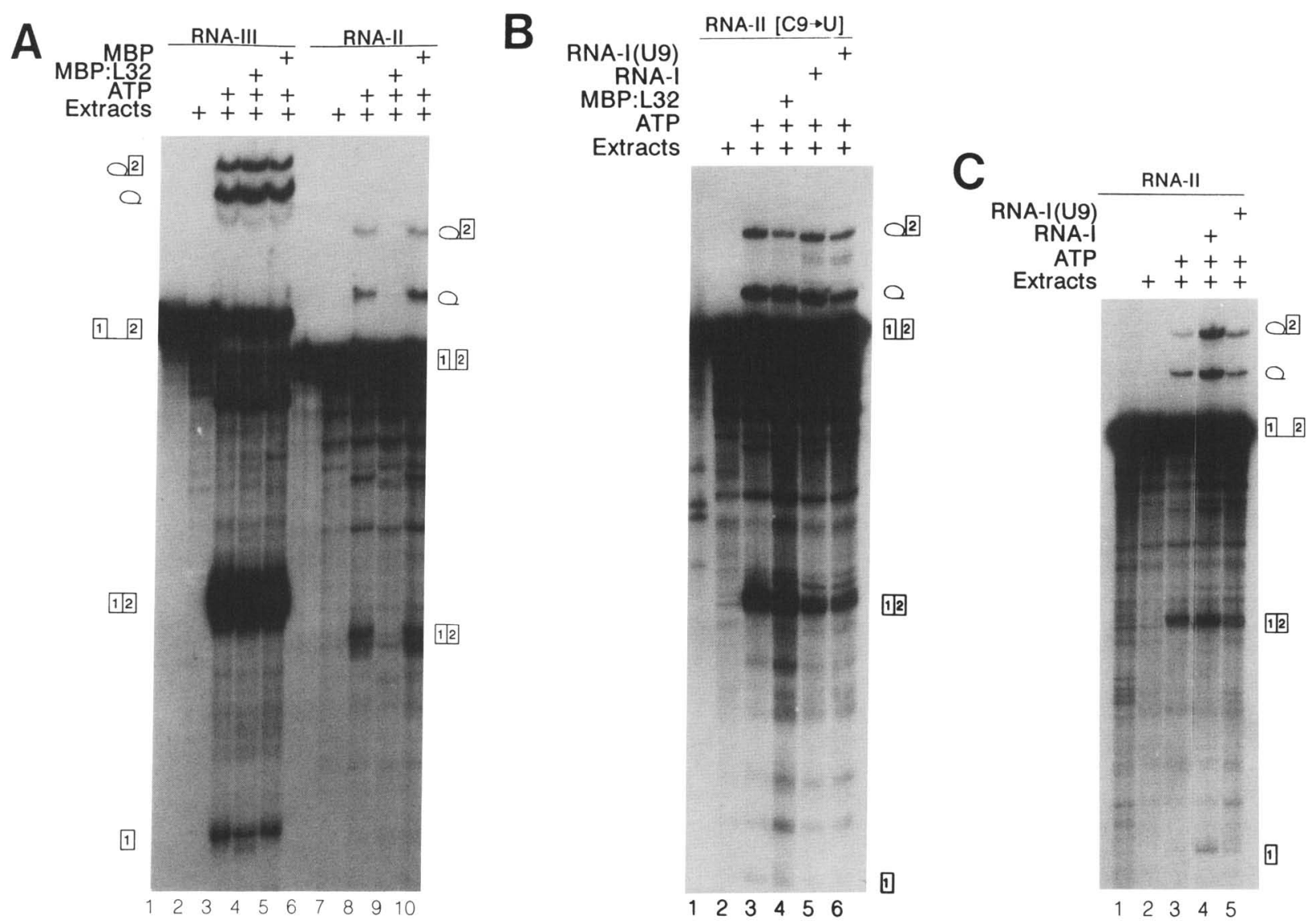

Figure 4. In vitro RPL32 splicing. The high background is attributable, at least in part, to the high specific activity of the probes (see Materials and methods). The MBP and MBP:L32 experiments were done adding $1 \mu \mathrm{g}(A)$ or $2 \mu \mathrm{g}(B)$ of MBP:L32 or $2 \mu \mathrm{g}$ of MBP to the extracts before they were mixed with substrates. $(A)$ In vitro splicing of the RPL32 substrate (RNA-II, lanes 6-10) compared with that of ACT1 (RNA-III, lanes 1-5). (Lanes 2, 7) Splicing extracts but no ATP, conditions in which no splicing activity should be observed. Free exon 1 from RNA-II is not detected in this gel. The multiple bands representing the spliced product have been attributed to polyadenylation in the extract (Séraphin and Rosbash 1990). (B) In vitro splicing of a mutant RPL32 substrate (C $\rightarrow$ U). Splicing extracts were supplemented with $2 \mu \mathrm{g}$ of MBP:L32 (lane 4) or preincubated with RNA-I (lane 5) or mutant RNA-I C, $\rightarrow$ U (lane 6). (C) In vitro splicing of the RPL32 substrate (RNA-II) in the presence of RNA-I. Splicing extracts were incubated with 25 ng of cold RNA-I (wild type in lane $4, \mathrm{C}_{9} \rightarrow \mathrm{U}$ mutant in lane 5) for 5-10 min at room temperature before being used in the reaction.

L32 in the extract could be titrated out. Comparing lanes 3 and 4 of Figure $4 \mathrm{C}$ shows that the splicing of RPL32 RNA is improved when the extracts are preincubated with RNA-I. The increase in splicing activity is correlated with the amount of RNA-I added (Fig. 5B).

The treatment of splicing extracts with RNA-I has no effect on their splicing activity toward a mutant RPL32 transcript whose splicing is not regulated in vivo (Fig. 4B, lane 5). Moreover, preincubation with a mutant RNA-I that does not bind the L32 protein [e.g., $\mathrm{C}_{9} \rightarrow \mathrm{U}$ /Fig. 3, lane 6)] does not lead to improved splicing either of the RPL32 wild-type substrate (Fig. 4C, lane 5) or of the $\mathrm{C}_{9} \rightarrow \mathrm{U}$ mutant substrate (Fig. 4B, lane 6).

These experiments demonstrate that splicing of the $R P L 32$ transcript is inhibited through binding of the $\mathrm{L} 32$ protein to the $5^{\prime}$ exon/intron sequences.

\section{$M B P: L 32$ inhibits spliceosome formation}

Because no lariat intermediates were observed either in the original in vivo experiments demonstrating the in hibition of splicing by L32 (Dabeva et al. 1986; Eng and Warner 1991) or in the in vitro experiments where splicing was abolished by MBP:L32 (Fig. 4A, lane 9), it seemed likely that inhibition occurs at an early stage in the splicing process. Much progress has been made recently in the analysis of the early steps of splicing (for review, see Woolford 1989; Rymond and Rosbash 1992). The first step appears to be the binding of the U1 snRNP to the transcript, probably at the 5' splice site, to form a commitment complex (CC) (Séraphin and Rosbash 1989, Ruby and Abelson 1988). Subsequently, in an ATP-dependent process, several splicing factors as well as the U2 snRNP bind, followed by the assembly of other components to form the complete spliceosome (Liao et al. 1992).

At what step does L32 block the splicing machinery? This point was addressed using native gel electrophoresis (Pikielny et al. 1986) (Fig. 6). When the RPL32 splicing substrate (RNA-II) is added to an extract in the ab- 


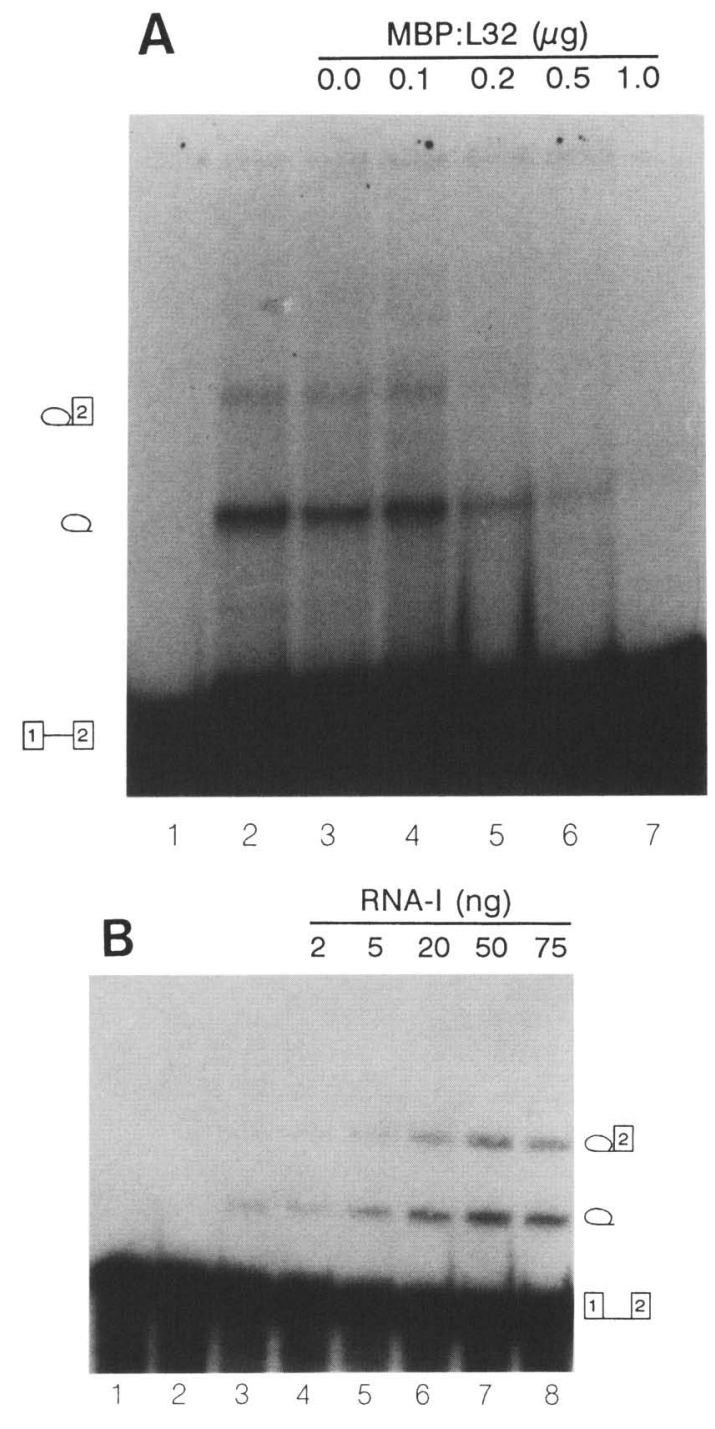

Figure 5. Regulation of RPL32 splicing. Only the top portion of the gels are shown. $A$ was exposed to film for a much longer time. (A) Inhibition of in vitro splicing by increasing amounts of MBP:L32. (Lane 1) Free probe (RNA-II); (lane 2) probe incubated with splicing extracts and ATP; (lanes 3-7) splicing buffer with indicated amounts of MBP:L32. $(B)$ Stimulation of in vitro splicing of the RPL32 transcript by incubation of the splicing extracts with RNA-I. (Lane 1) Free probe; (lane 2) probe with splicing extracts and without ATP; (lane 3) as in lane 2 but with ATP; (lanes $4-8$ ) splicing activity after addition to the splicing extracts of the indicated amounts of RNA-I, as described in Fig. $4 \mathrm{C}$.

sence of ATP, the RNA forms heterogeneus complexes (lane 2). A significant band is present at a position that appears to correspond to the CC (Pikielny et al. 1986). Addition of ATP to the intact extract permits assembly of a limited amount of more slowly migrating complexes, characteristic of intermediate and mature spliceosomes (lane 3). The presence of cold RNA-I, which stimulates splicing (see Fig. 4A), also stimulates the formation of the slowly migrating splicesome complexes at the expense of the CC (Fig. 6; lane 4), suggesting that L32 inhibits the formation of mature RPL32 spliceosomes. On the other hand, MBP:L32 abolishes completely the formation of the spliceosome complexes (Fig. 6, lane 5). The presence of MBP:L32 leads to a band migrating slightly behind the $\mathrm{CC}$ (Fig. 6, lanes 5-8) that cannot be a true spliceosome, as it is seen in the absence either of ATP (Fig. 6, lanes 6,7) or of U1 RNA (lanes 7,8). The specificity of the effect of the MBP:L32 on the formation of spliceosomes was explored using the $\mathrm{C}_{9} \rightarrow \mathrm{U}$ mutant substrate. Complexes involving this mutant transcript (Fig. 6, lanes 11,12) are unaffected by the presence of the MBP:L32 (lane 13).

These results demonstrate that the binding of L32 to its transcript blocks splicing at a step before the association with U2 snRNP. The presence of U1 snRNP is inferred by the formation of an apparent CC (Fig. 6, lanes $5,6)$ but a more positive identification was desirable.

\section{The nonspliceable complex contains U1 snRNP}

The structure predicted for the stem-loop in the RPL32 transcript (see Fig. 1A), on the basis of both experimental results (Eng and Warner 1991; Fig. 3) and computer analysis, would preclude the base-pairing of the U1 snRNP to the $5^{\prime}$ splice site, which is thought to initiate the splicing reaction.

Yet even in the presence of MBP:L32 an apparent CC is seen in Figure 6 (lanes 5,6$)$. We asked whether this had the characteristics of a true CC by depleting the extracts of Ul snRNA (Kretzner et al. 1987) (Fig. 6, lanes 7-9).

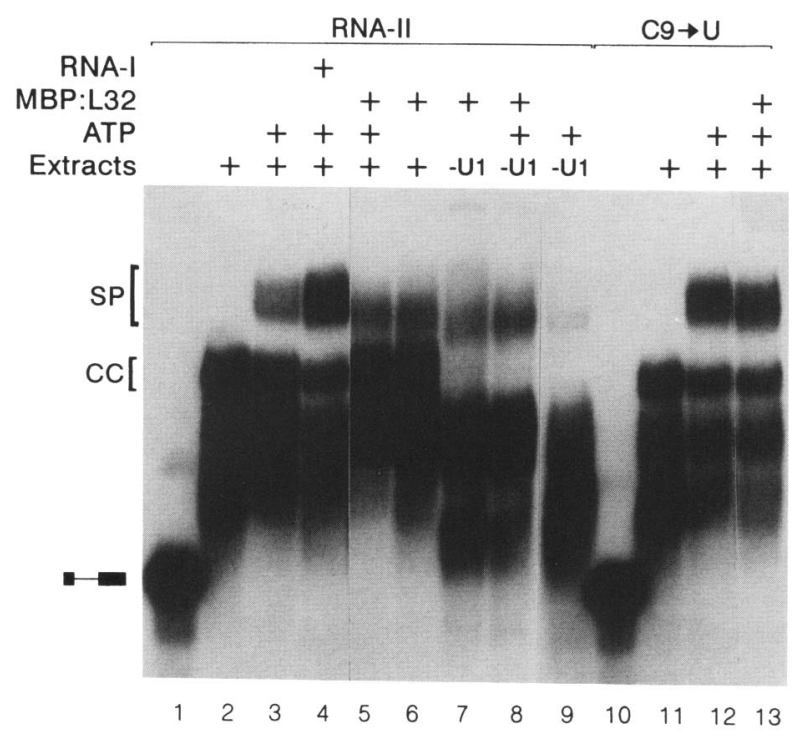

Figure 6. Formation of commitment complexes and mature spliceosomes by the RPL32 transcript. Labeled RNA-II, either wild type (lanes 1-9) or the $\mathrm{C}_{9} \rightarrow \mathrm{U}$ mutant (lanes 10-13), was incubated for $20 \mathrm{~min}$ at $23^{\circ} \mathrm{C}$ and loaded on a native gel as described by Séraphin and Rosbash (1989). The CCs and spliceosomes (SP) are named according to (Séraphin and Rosbash 1989). (-U1) Extracts depleted of U1 RNA (see Materials and methods|. 
Comparison of lane 9 with lanes 2 and 3 shows that depletion of U1 from the extract prevents the formation both of spliceosomes and of the putative CC. Similarly, comparison of lanes 7 and 8 with lanes 5 and 6 shows that the apparent CC formed in the presence of MBP:L32 cannot form after the depletion of U1 snRNA. Our preliminary conclusion is that the RPL32 transcript, even when bound to L32, can form a CC by interacting with U1 snRNP and presumably other factors.

The possibility remains that in the presence of MBP:L32 the formation of the apparent CC of the RPL32 transcript requires U1 snRNP only in a temporary manner and does not involve a stable association of Ul snRNA with the substrate. To demonstrate directly the association of Ul snRNA with the RPL32 transcript, we have used immunoaffinity purification of the MBP:L32RPL32 pre-mRNA complex using anti-MBP antibody (Arenas and Abelson 1993). The affinity-purified complex was then assayed for the presence of U1 RNA. The results show clearly (Fig. 7, lane 4) that a ternary complex between the RPL32 substrate MBP:L32 and U1 RNA can be formed in the extract and is sufficiently stable to withstand the affinity purification protocol, including the presence of a strong nonspecific competitor

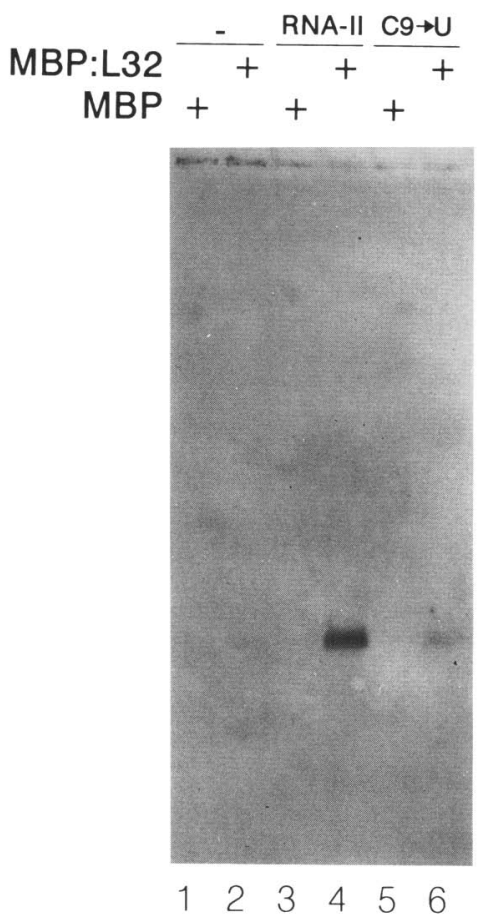

Figure 7. Presence of Ul RNA in the blocked CC. Extracts were supplemented with either MBP (lanes 1,3,5) or MBP:L32 $($ lanes 2,4,6). The substrates [(Lanes 1,2) none; (lanes 3,4) RNAII; (lanes 5,6$)$ mutant RNA-II $\left(C_{9} \rightarrow\right.$ U)] were added in the presence of ATP for $20 \mathrm{~min}$ at $23^{\circ} \mathrm{C}$. Complexes were immunoprecipitated with anti-MBP antibody as described in Materials and methods. RNA was prepared from the immunoprecipitation, analyzed on a Northern blot that was hybridized with a probe complementary to Ul RNA. The location of Ul RNA was verified from an adjacent lane of total RNA. such as heparin. Omission of the RPL32 transcript (lane 2), the use of MBP rather than MBP:L32 (lanes 1,3,5), or the use of the $\mathrm{C}_{9} \rightarrow \mathrm{U}$ mutant substrate (lanes 5,6 ) yields little if any Ul snRNA. As expected, as no spliceosomes were formed in the presence of MBP:L32 (Fig. 6, lane 6), U2 RNA was not detected in complexes formed between RNA-II and MBP:L32 (data not shown).

We conclude that even when bound to L32, the RPL32 transcript can associate with U1 RNA to form what appears to be a CC. The presence of L32 blocks splicing by preventing the next step, the ATP-dependent association of the U2 snRNP and/or other components of the splicing apparatus.

\section{Discussion}

On the basis of a variety of experiments carried out in vivo, we had postulated that ribosomal protein L32 would bind to its transcript to inhibit its splicing (Dabeva et al. 1986). The results described above have confirmed this prediction entirely. The binding of L32 to the transcript requires no auxiliary factors. Furthermore, the identification of the key nucleotides involved in the regulation has also been confirmed. The details of the interactions, however, are somewhat different than we had predicted, leading to the development of a new understanding of the mechanism by which regulation takes place.

The regulation of splicing of the RPL32 transcript shares some features with other regulation systems and differs in others. Many of the proteins involved in the regulation of splicing have one or both of the characteristics in common: (1) a stretch rich in arginine and serine, and (2) a consensus RNA-binding site, first identified in proteins binding to heterogenous RNA (hnRNA) and mRNA (Dreyfuss et al. 1988). L32 has neither, nor do any of the other ribosomal proteins. We presume that L32 binds to its transcript using the same motif with which it binds to the rRNA.

In many cases, negative regulation occurs at a splice site that is somewhat unfavorable. An unusually long stretch between the branchpoint and the 3 ' splice site is involved in the regulated splicing of the rat $\alpha$-tropomyosin transcript (Smith and Nadal-Ginard 1989; Mullen et al. 1991) and of the autoregulated splice of the Drosophila su $\left(w^{a}\right)$ transcript (Spikes and Bingham 1992), among others. The transcript encoding ribosomal protein Ll of Xenopus, whose splicing is subject to regulation, has a suboptimal $3^{\prime}$ acceptor site /Caffarelli et al. 1992). In the other instance of regulated splicing described in S. cerevisiae, the MER2 transcript has a noncanonical $5^{\prime}$ splice site, G/GUUCGU. . ., that should form one less base pair with U1 RNA. Splicing occurs naturally only when the MER1 gene product is present, but the need for Merlp is relieved if $M E R 2$ is mutated to improve the interaction with U1, even outside the usual site of pairing (Nandabalan et al. 1993). Although the $5^{\prime}$ splice site of the RPL32 transcript is G/GUCAGU. . . rather than the canonical G/GUAUGU. . ., it can form the same number of base pairs with U1 RNA. Under 
optimal growth conditions, where there is presumably little free $\mathrm{L} 32$, the transcript is spliced effectively in vivo with a ratio of mRNA to pre-mRNA of $>50: 1$ (Dabeva et al. 1986). Because the half-life of RPL32 mRNA is $16 \mathrm{~min}$ (Kim and Warner 1983), the half-time for splicing must be $\sim 15 \mathrm{sec}$. Introduction of the canonical $5^{\prime}$ splice site, together with a compensatory mutation at position 6 (Fig. 1A) to maintain base-pairing, has little effect on regulation of splicing in vivo (Eng and Warner 1991) or in vitro (data not shown). Thus, the regulation of splicing of the RPL32 transcript is not the result of a noncanonical splice site but of the presence of L32.

In several instances, the RNA sequences responsible for the regulation of splicing have been identified. Thus, a series of repeats in the downstream exon of the $d s x$ transcript bind the tra and tra-2 proteins (Nagoshi and Baker 1990; Hedley and Maniatis 1991; Inoue et al. 1992; Tian and Maniatis 1993). A sequence in the $5^{\prime}$ exon of the P-element transposase binds proteins not yet unidentified (Siebel et al. 1992). Sxl binds to a polypyrimidine tract specific to both the $S_{X I}$ and the tra sex-specific $3^{\prime}$ splice site (Valcarcel et al. 1993). However, only in rare instances has an RNA secondary structure been implicated in the regulation of splicing (for review, see Balvay et al. 1993). In K. lactis, a distal 3' splice site is used apparently because the proximal one is involved in a secondary structure (Deshler and Rossi 1991). Similar situations occur for regulated splicing of adenovirus transcripts (Chebli et al. 1989; Domenjoud et al. 1993) and of an immunoglobulin transcript (Watakabe et al. 1989). Exon 6A of the chicken tropomyosin gene is used preferentially to exon $6 \mathrm{~B}$ in myoblasts because the $3^{\prime}$ acceptor site of the latter is within a stem. Mutations that weaken the stem permit utilization of exon $6 \mathrm{~B}$; compensatory mutations restore the regulation (Libri et al. 1991). Presumably, as yet undescribed tissue-specific proteins permit the use of exon $6 \mathrm{~B}$ in differentiated skeletal muscle.

The situation for L32 is clearer. Not only have we shown that L32 binds to the transcript whose splicing is regulated, but we have considerable evidence about the structure of the key regions of the transcript. The binding results in Figure 3 match exactly the data obtained previously on the regulation of splicing in vivo /Eng and Warner 1991). The change of a single base $>50$ nucleotides distant from the $5^{\prime}$ splice site will abolish both the binding of $\mathrm{L} 32$ to its transcript in vitro and the regulation of splicing in vivo.

The structure depicted in Figure 1A was derived from comparing the sequences of the $5^{\prime}$ exons of RPL32 from $S$. cerevisiae and $K$. lactis and from computer predictions (Zuker 1991). It was supported by the effects of numerous mutations on the regulation of splicing (Eng and Warner 1991). However, confirmation of the lower stem was less secure. Several mutations could not be examined because they would have abolished splicing altogether. In testing mutant transcripts for the binding of L32 in vitro (Fig. 3), we confirm the importance of $G_{61}$ and $\mathrm{G}_{62}$ on either side of the $5^{\prime}$ splice site. In any case, the structure of the lower stem is probably more com- plex than shown in Figure 1A. For instance, the mutant $\mathrm{U}_{63} \rightarrow \mathrm{C}$ retains some binding activity (Fig. 3 , lane 11 ). Also, the mutant $G_{10} \rightarrow A$, which should strengthen the stem, actually abolishes regulation of splicing (Eng and Warner 1991). Although it is clear that the upper stem is essential for the regulation of splicing, and that the loop from nucleotides 18 to 49 plays little role, understanding the three-dimensional arrangement of the complex will have to wait for better methods.

The predicted stability of the structure shown in Figure $1 \mathrm{~A}$ is rather low, with a $\Delta \mathrm{G}$ of $<9 \mathrm{kcal} / \mathrm{mole}$ (Zuker 1991). This is far less than necessary to block splicing (Solnick and Lee 1987). Originally, we hypothesized that L32 stabilized this structure, thereby preventing access of U1 RNA (Eng and Warner 1991). However, Figures 6 and 7 show that U1 RNA is associated with the RPL32 transcript even in the presence of MBP:L32. Thus, there is a ternary complex in which U1 RNA can associate with the substrate in a presplicing complex, whereas L32 remains bound. The presence of $L 32$ prevents the next steps of splicing, namely the ATP-dependent association of U2 RNA and the subsequent formation of the complete spliceosome (Ruby et al. 1993). The detailed interactions of the RNAs remain speculative. Although we cannot exclude the possibility that the lower stem remains intact during the interaction of the $5^{\prime}$ splice site with U1 RNA, it seems more likely that U1 RNA displaces nucleotides 6-9 (GACC) from their base-pairing with the 5' splice site without eliminating the binding of L32. What is the role of the purine-rich bulges connecting the two stems?

The fact that L32 blocks the splicing of its transcript at a step after the association of the substrate with U1 RNA and before its association with U2 RNA may provide a new experimental tool to dissect this key step in splicing.

The structure described in Figure 1A is composed almost entirely of the first exon. The spliced transcript can form the same structure, except that the lower stem can form only $3 \mathrm{bp}$ instead of 4 . The mutant $\mathrm{U}_{63} \rightarrow \mathrm{C}$ (Fig. 3, lane 11) has the equivalent sequence. L32 binds to this structure, but only weakly. Nevertheless, the presence of L32 has a substantial effect on the efficiency of translation of the spliced mRNA (Dabeva and Warner 1993).

The in vitro splicing assay used above has the advantage that it can be manipulated in both directions. Addition of MBP:L32 inhibits specifically the splicing of the RPL32 transcript; addition of RNA-I stimulates specifically the splicing of the RPL32 transcript, presumably by competing for the L32 that is in the extract. It is not clear whether the L32 in the extract represents molecules not yet assembled into ribosomes, or molecules that have been stripped from ribosomes during the preparation of the extract. The loss of L32 from a very small proportion of the ribosomes would be sufficient.

The original observation that $\mathrm{L} 32$ could regulate the splicing of its own transcript provided a rationale for the presence of introns in two-thirds of the ribosomal protein genes, whereas they are rare in other genes of $S$. cerevisiae (Woolford 1989). However, assays for the reg- 
ulation of splicing of several other ribosomal protein transcripts have failed in that no regulated accumulation of unspliced precursor molecules was observed. We now suggest an explanation. The formation of a CC with $\mathrm{Ul}$ RNA may lead to stabilization of the RPL32 transcript. In the case of the numerous prp mutations that have been identified because of the accumulation of unspliced transcripts, the blockage at the nonpermissive temperature invariably occurs at a step subsequent to the formation of a CC (Woolford 1989). Perhaps, then, the splicing of other ribosomal protein transcripts is regulated, but in such a way that the unspliced transcript is degraded so rapidly that it is undetectable. For example, the regulated splicing of the ribosomal protein Ll transcript of Xenopus leads to a U1 RNA-dependent degradation of the transcript (Fragapane et al. 1993). Using the in vitro splicing assay described above may permit us to detect the regulation of splicing of other ribosomal protein transcripts using decoy transcripts to compete for free ribosomal proteins within the extract. Our use of RNA-I in the splicing experiments of Figures 4, 5, and 6 was sufficient to demonstrate the regulation of splicing of the RPL32 transcript.

The finding of a more general regulation of splicing of ribosomal protein transcripts would not only provide a satisfying explanation for the presence of introns in ribosomal protein genes, but would also extend the parallel between $E$. coli and $S$. cerevisiae. In the former, the balance between rRNA and ribosomal proteins is maintained because certain ribosomal proteins, when in excess over the rRNA, bind to their mRNA to prevent translation of an entire operon. In a eukaryote, as translation and ribosome assembly occur in different compartments of the cell, a more economical way of maintaining the balance between rRNA and ribosomal proteins would be to regulate a nuclear event, such as splicing.

\section{Materials and methods}

\section{Fusion protein and strains}

The MBP:L32 fusion protein gene was constructed as follows: The L32 fragment was obtained by PCR of exon II (nucleotides 234-554, taking as position +1 the $A$ of the initiation codon in exon I) of the RPL32 gene and cloned between the StuI and SalI sites of the vector pMALc (BioLabs). Factor Xa digestion of the product would yield the $\mathrm{L} 32$ protein as it is in vivo. Purification of the fusion protein by absorption to and elution from an amylose column followed the manufacturer's instructions (ProFusion kit, BioLabs).

To express the MBP:L32 in yeast cells its gene was modified to put an $X$ hoI site at the $5^{\prime}$ end and the $3^{\prime}$-untranslated region of the RPL32 gene at the $3^{\prime}$ end, and then used to replace the SEP1 gene of pRDK249 (Johnson and Kolodner 1991) to yield plasmid pRDKFP.

The diploid strain JV1 (RPL32/rpl32::HIS3) was constructed by disruption of one RPL32 gene in the homozygous diploid W303 (Mata/ $\alpha$, ade2-1, his3-11, leu2-3,112, trp1-1, ura3-1, can1-100) using the one-step gene disruption technique (Rothstein 1983). Haploid Mata and Mata strains were derived from spores of W303. Strains were subjected to transformation by the lithium acetate procedure (Ito et al. 1983).

\section{RNA probes and substrates}

For the transcripts of RPL32 and its mutants, a sequence corresponding to the entire transcript of RPL32 was amplified by PCR and cloned in pGEM3Z (Promega). For preparation of RNA-I (nucleotides 1-75, taking as +1 the start of transcription; see Fig. 1C), the plasmid was digested with NlaIII, then treated with Klenow and transcribed with $\mathrm{T} 7$ polymerase. For preparation of RNA-II (nucleotides 1-360), the plasmid was cut with Ddel. pACT was constructed by cloning the PCR fragment representing nucleotides 606-1052 of the yeast actin gene /GenBank accession no. 100026) $(\mathrm{Ng}$ and Abelson 1980) in the SacI and EcoRI sites of pKS (Stratagene). For the actin probe pACT was digested with EcoRI and transcribed with $\mathrm{T} 7$ polymerase.

The S10 transcript was made by T7 transcription of pS10A-1 digested with DraI. pS10A-1 is a pT7/T3-18 clone of the RPS10 transcript (Johnson and Warner 1987). For probing Northern blots, Ul antisense RNA was synthesized from a pSK subclone of pT7U1 plasmid (kindly provided by Dr. J. Arenas, Caltech, Pasadena, CA).

\section{In vitro transcription}

In vitro transcriptions were performed in $20 \mu \mathrm{l}$ of $40 \mathrm{mM}$ Tris$\mathrm{HCl}$ (pH 7.9), $6 \mathrm{~mm} \mathrm{MgCl}_{2}, 10 \mathrm{~mm}$ DTT, 2 mM spermidine, 500 $\mu \mathrm{M}$ all NTPs except UTP, $200 \mathrm{ng}$ of DNA /digested, proteinase $\mathrm{K}$-treated and phenol-chloroform extracted), 20 units of RNasin (Promega), and 10-20 units of T7 or SP6 RNA polymerase (Promega, Biolabs). For mobility-shift substrates the cold UTP was $500 \mu \mathrm{M}$ with $100 \mu \mathrm{Ci}$ of $\left[\alpha-{ }^{32} \mathrm{P}\right] \mathrm{UTP}(800 \mathrm{Ci} / \mathrm{mmole}, \mathrm{NEN})$. For in vitro splicing substrates cold UTP was $20 \mu \mathrm{M}$ with 160 $\mu \mathrm{Ci}$ of $\left[\alpha^{-32} \mathrm{P}\right] \mathrm{UTP}$. Riboprobes for hybridization were synthesized using $200-250 \mu \mathrm{Ci}$ of $\left[\alpha^{-32} \mathrm{P} \mid \mathrm{UTP}\right.$. After $1 \mathrm{hr}$ at $37^{\circ} \mathrm{C}, 1 \mathrm{unit}$ of RQ1 DNase (Promega) was added and the reaction was incubated $15 \mathrm{~min}$ more. When the transcript was to be gel purified (as for the splicing reactions), this step was omitted. Cold RNA competitors were synthesized in $100 \mu \mathrm{l}$ reactions, in the same buffer, containing $0.5 \mathrm{~mm}$ of all nucleotides, 100 units of $\mathrm{RNa}$ sin, $0.5-2 \mu \mathrm{g}$ of DNA, and $20-40$ units of RNA polymerase. The DNA template was digested with 2 units of RQ1 DNase. RNA was purified by phenol-chloroform extraction, precipitated with ammonium acetate, and checked by gel electrophoresis.

\section{Site-directed mutagenesis}

The in vitro mutagenesis was done by cloning the product of a PCR performed using mutant oligonucleotides. For some mutations a circular PCR method was used (Imai et al. 1991). In all cases, the products were sequenced. The RPL32 mutant with an AAG insertion after the first AUG is described elsewhere (Eng and Warner 19911.

\section{Mobility-shift assays}

RNA probes were dissolved in renaturation buffer (RB), containing $30 \mathrm{~mm}$ Tris- $\mathrm{HCl}(\mathrm{pH} 7.5), 350 \mathrm{mM} \mathrm{KCl}$, and $10 \mathrm{~mm} \mathrm{DTT}$, heated at $65^{\circ} \mathrm{C}$ for $10 \mathrm{~min}$ and then slowly cooled to binding temperature. This step could be omitted for the short RNAs. Typical binding reactions were performed in $20 \mu \mathrm{l}$ of $30 \mathrm{mM}$ Tris- $\mathrm{HCl}$ (pH 7.5), $75 \mathrm{~mm} \mathrm{KCl}, 2 \mathrm{mM} \mathrm{MgCl}$, $1 \mathrm{~mm}$ DTT, 50 $\mathrm{ng} / \mu \mathrm{l}$ of BSA (Promega), $40 \mathrm{ng} / \mu \mathrm{l}$ of tRNA (wheat germ), 5-50 fmoles of probe, $50 \mathrm{ng}$ of MBP:L32 and, when indicated, $25-50$ ng of cold RNA competitor. Reactions were incubated at $25^{\circ} \mathrm{C}$ for $20 \mathrm{~min}$ and loaded immediately in a running acrylamide gel. For short probes (RNA-I; Fig. 1C) gels were 6\% acrylamide (acry- 
lamide/bisacrylamide ratio of 30:0.51, 0.5\% agarose, $0.25 \times \mathrm{TBE}$, with recirculation.

\section{In vitro splicing}

Because of the poor in vitro splicing efficiency of the RPL32 transcript, we used RNA probes of higher specific activity than usual. Although these probes are degraded rapidly (Yisraeli and Melton 1989), they allow us to detect the reaction on RPL32 substrates with more sensitivity. For consistency, actin substrates were labeled in the same way, although the background in splicing gels is substantially increased.

Splicing extracts were prepared (Lin et al. 1985; Cheng et al. $1990)$ from strain W303. Splicing reactions were performed following standard procedures (Cheng et al. 1990) but using 0.2-0.5 nmoles of RNA substrate. At the end of the reaction the sample was treated with proteinase $\mathrm{K}$, with phenol- $\mathrm{CHCl}_{3}$, and the RNA precipitated with ethanol, washed, redissolved in loading buffer, and the radioactivity determined. The proportion of CPM recovered was independent of whether the substrate was spliced or not. The same number of counts per minute were loaded in each gel lane.

U1 snRNP depletion was carried out using the oligonucleotide-directed RNase $\mathrm{H}$ method, as described (Kretzner et al. 1987). The oligonucleotide sequence was CTTAAGGTAAGTAT, complementary to the first 14 bases of UI RNA.

Native gel analysis was according to Séraphin and Rosbash (1989), but omitting the final addition of loading buffer. In these experiments the extracts were depleted of ATP (Liao et al. 1992).

\section{Immunoprecipitations}

Splicing complexes containing the MBP:L32 were isolated by immunoprecipitation (Arenas and Abelson 1993). Splicing reactions $(20 \mu \mathrm{l})$ were set up with $50-100$ fmoles of RNA under different conditions (see Results). After $20 \mathrm{~min}$ at $23^{\circ} \mathrm{C}, 80 \mu \mathrm{l}$ of SPL buffer [50 mM K $\mathrm{HPO}_{4}$ (pH 7.2), $2.5 \mathrm{mM} \mathrm{MgCl}, 1 \mathrm{~mm} \mathrm{DTT}$ ], with $5 \mu \mathrm{g} / \mu \mathrm{l}$ of heparin (Sigma), was added and the reaction was incubated in ice for $10 \mathrm{~min}$. To the reaction mixture $20 \mu \mathrm{l}$ of anti-MBP-protein A-Sepharose beads was added, prepared by mixing $200 \mu$ lof rabbit anti-MBP antiserum (BioLabs) and $\sim 300$ $\mu \mathrm{l}$ of protein A-Sepharose (PAS, Zymed). After $1 \mathrm{hr}$ of gentle rocking at $4^{\circ} \mathrm{C}$, beads were washed three times $\left(20 \mathrm{~min}\right.$ at $\left.4^{\circ} \mathrm{C}\right)$ with $200 \mu \mathrm{l}$ of SPL-150 mM KCl, resuspended in $90 \mu \mathrm{l}$ of NET buffer [50 mM Tris- $\mathrm{HCl}(\mathrm{pH} 7.5), 0.1 \% \mathrm{NP}-40,1 \mathrm{mM}$ EDTA], transferred to a new tube, brought to a final concentration of 5 mM EDTA, $0.1 \%$ SDS, $10 \mathrm{ng} / \mu \mathrm{l}$ of $E$. coli tRNA, and $10 \mathrm{ng} / \mu \mathrm{l}$ of proteinase $\mathrm{K}$, and digested for $15 \mathrm{~min}$ at $37^{\circ} \mathrm{C}$. The RNA was extracted with phenol-chloroform, precipitated, and washed.

\section{Acknowledgments}

We are grateful to Dr. S.P. Johnson for carrying out earlier experiments, to Drs. J. Woolford, J. Arenas, H. Colot, and D.S. McPheeters for useful discussions, to Dr. R. Raz for critical reading of the manuscript, to $M$. Studeny for technical assistance, and to A. Greaney for assistance with the manuscript. This research was supported by American Cancer Society grant NP-793 (to JRW) and National Institutes of Health grant CA13330, which supports the Cancer Center of the Albert Einstein College of Medicine. J.V. has been the holder of a Fulbright Fellowship from the Spanish Ministry of Education.

The publication costs of this article were defrayed in part by payment of page charges. This article must therefore be hereby marked "advertisement" in accordance with 18 USC section 1734 solely to indicate this fact.

\section{References}

Arenas, J.E. and J.N. Abelson. 1993. The Saccharomyces cerevisiae PRP21 gene product is an integral component of the prespliceosome. Proc. Natl. Acad. Sci. 90: 6771-6775.

Baker, B.S. 1989. Sex in flies: The splice of life. Nature 340: $512-524$.

Balvay, L., D. Libri, and M.Y. Fiszman. 1993. Pre-mRNA secondary structure and the regulation of splicing. BioEssays 15: 165-169.

Caffarelli, E., P. Fragapane, and I. Bozzoni. 1992. Inefficient in vitro splicing of the regulatory intron of the $\mathrm{L} 1$ ribosomal protein gene of $X$. laevis depends on suboptimal splice site sequences. Biochem. Biophys. Res. Commun. 183: 680-687.

Chebli, K., R. Gattoni, P. Schmitt, G. Hildwein, and J. Stevenin. 1989. The 216-nucleotide intron of the E1A pre-mRNA contains a hairpin structure that permits utilization of unusually distant branch acceptor. Mol. Cell. Biol. 9: 4852-4861.

Cheng, S.-C., A.J. Newman, R.-J. Lin, G.D. McFarland, and J.N. Abelson. 1990. Preparation and fractionation of yeast splicing extract. Methods Enzymol. 181: 89-96.

Dabeva, M.D. and J.R. Warner. 1993. Ribosomal protein L32 of Saccharomyces cerevisiae regulates both splicing and translation of its own trancript. J. Biol. Chem. 268 (in press).

Dabeva, M.D., M.A. Post Beittenmiller, and J.R. Warner. 1986. Autogenous regulation of splicing of the transcript of a yeast ribosomal protein gene. Proc. Natl. Acad. Sci. 83: 58545857.

Deshler, J.O. and J.J. Rossi. 1991. Unexpected point mutations activate cryptic $3^{\prime}$ splice sites by perturbing a natural secondary structure within a yeast intron. Genes \& Dev. 5: 1252-1263.

Domenjoud, L., H. Gallinaro, L. Kister, S. Meyer, and M. Jacob. 1993. Identification of a specific exon sequence that is a major determinant in the selection between a natural and a cryptic 5' splice site. Mol. Cell. Biol. 11: 4581-4590.

Dreyfuss, G., M.S. Swanson, and S. Piñol-Roma. 1988. Heterogeneous nuclear ribonucleoprotein particles and the pathway of mRNA formation. Trends Biochem. Sci. 13: 86-91.

Eng, F.J. and J.R. Warner. 1991. Structural basis for the regulation of splicing of a yeast messenger RNA. Cell 65: 797-804.

Fragapane, P., S. Prislei, A. Michienzi, E. Caffarelli, and I. Bozzoni. 1993. A novel small nucleolar RNA (U16) is encoded inside a ribosomal protein intron and originates by processing of the pre-mRNA. EMBO I. 12: 2921-2928.

Ge, H. and J.L. Manley. 1990. A protein factor, ASF, controls cell-specific alternative splicing of SV40 early pre-mRNA in vitro. Cell 62: 25-34.

Hedley, M.L. and T. Maniatis. 1991. Sex-specific splicing and polyadenylation of $d s x$ pre-mRNA requires a sequence that binds specifically to tra-2 protein in vitro. Cell 65: 579-586.

Imai, Y., Y. Matsushima, T. Sugimura, and M. Terada. 1991. A simple and rapid method for generating a deletion by PCR. Nucleic Acids Res. 19: 2785.

Inoue, K., K. Hoshijima, I. Higuchi, H. Sakamoto, and Y. Shimura. 1992. Binding of the Drosophila transformer and transformer-2 proteins to the regulatory elements of doublesex primary transcript for sex-specific RNA processing. Proc. Natl. Acad. Sci. 89: 8092-8096.

Ito, H., K. Fukuda, K. Murata, and A. Kimura. 1983. Transformation of intact yeast cells treated with alkali cations. $J$. Bacteriol. 153: 163-168. 
Johnson, A.W. and R.D. Kolodner. 1991. Strand exchange protein from Saccharomyces cerevisiae. I. Biol. Chem. 266: 14046-14054.

Johnson, S.P. and J.R. Warner. 1987. Phosphorylation of the Saccharomyces cerevisiae equivalent of ribosomal protein S6 has no detectable effect on growth. Mol. Cell Biol. 7: 13381345.

Kim, C.H. and J.R. Warner. 1983. Messenger RNA for ribosomal proteins in yeast. J. Mol. Biol. 165: 79-89.

Krainer, A.R., G.C. Conway, and D. Kozak. 1990. The essential pre-mRNA splicing factor SF2 influences $5^{\prime}$ splice site selection by activating proximal sites. Cell 62: 35-42.

Kretzner, L., B.C. Rymond, and M. Rosbash. 1987. S. cerevisiae U1 RNA is large and has limited primary sequence homology to metazoan U1 snRNA. Cell 50: 593-602.

Liao, X.C., H.V. Colot, Y. Wang, and M. Rosbash. 1992. Requirements for U2 snRNP addition to yeast pre-mRNA. Nucleic Acids Res. 20: 4237-4245.

Libri, D., A. Piseri, and M.Y. Fiszman. 1991. Tissue specific splicing in vivo of the beta-tropomyosin gene: Dependence on an RNA secondary structure. Science 252: 1842-1845.

Lin, R.-J., A.J. Newman, S.-C. Cheng, and J.N. Abelson. 1985. Yeast mRNA splicing in vitro. J. Biol. Chem. 260: 1478014792.

Maina, C.V., P.D. Riggs, A.G. Grandea, B.E. Slatko, L.S. Moran, J.A. Tagliamonte, L.A. McReynolds, and C. Guan. 1988. A vector to express and purify foreign proteins in Escherichia coli by fusion to, and separation from, maltose binding protein. Gene 74: 365-373.

McKeown, M. 1992. Alternative mRNA splicing. Annu. Rev. Cell Biol. 8: 133-155.

Mullen, M.P., C.W. Smith, J.G. Patton, and B. Nadal Ginard. 1991. Alpha-tropomyosin mutually exclusive exon selection: Competition between branchpoint/polypyrimidine tracts determines default exon choice. Genes \& Dev. 5: 642655.

Nadal-Ginard, B., C.W. Smith, J.G. Patton, and R.E. Breitbart. 1991. Alternative splicing is an efficient mechanism for the generation of protein diversity: Contractile protein genes as a model system. Adv. Enz. Reg. 31: 261-286.

Nagoshi, R.N. and B. Baker. 1990. Regulation of sex-specific RNA splicing at the Drosophila doublesex gene: cis-acting mutations in exon sequences alter sex specific RNA splicing patterns. Genes \& Dev. 4: 89-97.

Nandabalan, K., L. Price, and G.S. Roeder. 1993. Mutations in U1 snRNA bypass the requirement for a cell type-specific RNA splicing factor. Cell 73: 407-415.

$\mathrm{Ng}, \mathrm{R}$. and J.N. Abelson. 1980. Isolation and sequence of the gene for actin in Saccharomyces cerevisiae. Proc. Natl. Acad. Sci. 77: 3912-3916.

Pikielny, C.W., B.C. Rymond, and M. Rosbash. 1986. Electrophoresis of ribonucleoproteins reveals an ordered assembly pathway of yeast splicing complexes. Nature 324: 341-375.

Rio, D.C. 1992. RNA processing. Curr. Opin. Cell Biol. 4: 444 452.

Rothstein, R.J. 1983. One-step gene disruption in yeast. Methods Enzymol. 101: 202-211.

Ruby, S.W. and J. Abelson. 1988. An early hierarchic role of U1 small nuclear ribonucleoprotein in spliceosome assembly. Science 242: 1028-1035.

Ruby, S.W., T.-H. Chang, and J. Abelson. 1993. Four yeast spliceosomal proteins $(P R P 5, P R P 9, P R P 11$, and $P R P 21$ interact to promote U2 snRNP binding to pre-mRNA. Genes \& Dev. 7: 1909-1925.

Rymond, B.C. and M. Rosbash. 1992. Yeast pre-mRNA splicing. In The molecular and cellular biology of the yeast Saccha- romyces: Gene expression (ed. E.W. Jones, J.R. Pringle, and J.R. Broach|, pp. 143-193. Cold Spring Harbor Laboratory Press, Cold Spring Harbor, New York.

Séraphin, B. and M. Rosbash. 1989. Identification of functional U1 snRNA-Pre-mRNA complexes committed to spliceosome assembly and splicing. Cell 59: 349-358.

1990. Exon mutations uncouple 5' splice site selection from Ul snRNA pairing. Cell 63: 619-629.

Siebel, C.W., L.D. Fresco, and D.C. Rio. 1992. The mechanism of somatic inhibition of Drosophila P-element pre-mRNA splicing: Multiprotein complexes at an exon pseudo-5' splice site control Ul snRNP binding. Genes \& Dev. 6: 1386-1401.

Smith, C.W. and B. Nadal-Ginard. 1989. Mutually exclusive splicing of alpha-tropomyosin exons enforced by an unusual lariat branch point location: Implications for constitutive splicing. Cell 56: 749-758.

Smith, C.W.J., I.G. Patton, and B. Nadal-Ginard. 1989. Alternative splicing in the control of gene expression. Annu. Rev. Genet. 23: 527-577.

Solnick, D. and S.I. Lee. 1987. Amount of RNA secondary structure required to induce an alternative splice. Mol. Cell. Biol. 7:3194-3198.

Spikes, D. and P.M. Bingham. 1992. Analysis of spliceosome assembly and the structure of a regulated intron in Drosophila in vitro splicing extracts. Nucleic Acids Res. 20: 5719 5727.

Tian, M. and T. Maniatis. 1992. Positive control of pre-mRNA splicing. Science 256: 237-240.

-1993. A splicing enhancer complex controls alternative splicing of doublesex pre-mRNA. Cell 74: 105-114.

Valcarcel, J., R. Singh, P.D. Zamore, and M.R. Green. 1993. The protein Sex-lethal antagonizes the splicing factor U2AF to regulate alternative splicing of transformer pre-mRNA. $\mathrm{Na}$ ture 362: 171-175.

Watakabe, A., K. Inoue, H. Sakamoto, and Y. Shimura. 1989. A secondary structure at the 3 splice site affects the in vitro reaction of mouse immunoglobulin mu chain pre-mRNAs. Nucleic Acids Res. 17: 8159-8169.

Woolford, J.L. Jr. 1989. Nuclear pre-mRNA splicing in yeast. Yeast 5: 439-457.

Yisraeli, J.K. and D.A. Melton. 1989. Synthesis of long, capped transcripts in vitro by SP6 and T7 RNA polymerases. Methods Enzymol. 180: 42-50.

Zuker, M. 1991. Suboptimal sequence alignment in molecular biology. Alignment with error analysis. I. Mol. Biol. 221: 403-420. 


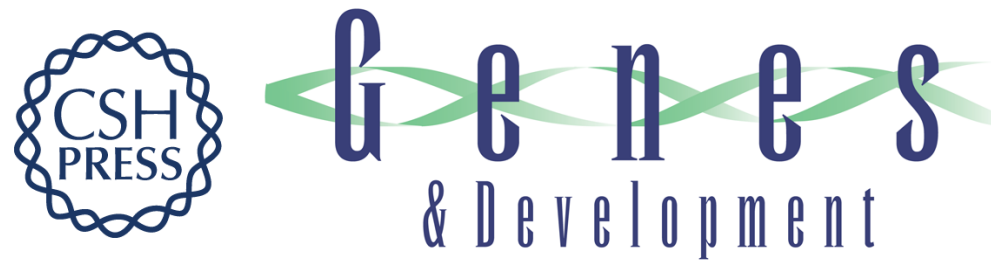

\section{Regulation of splicing at an intermediate step in the formation of the spliceosome.}

$\mathrm{J}$ Vilardell and J R Warner

Genes Dev. 1994, 8:

Access the most recent version at doi:10.1101/gad.8.2.211

References This article cites 51 articles, 18 of which can be accessed free at:

http://genesdev.cshlp.org/content/8/2/211.full.html\#ref-list-1

License

Email Alerting

Service

Receive free email alerts when new articles cite this article - sign up in the box at the top right corner of the article or click here.

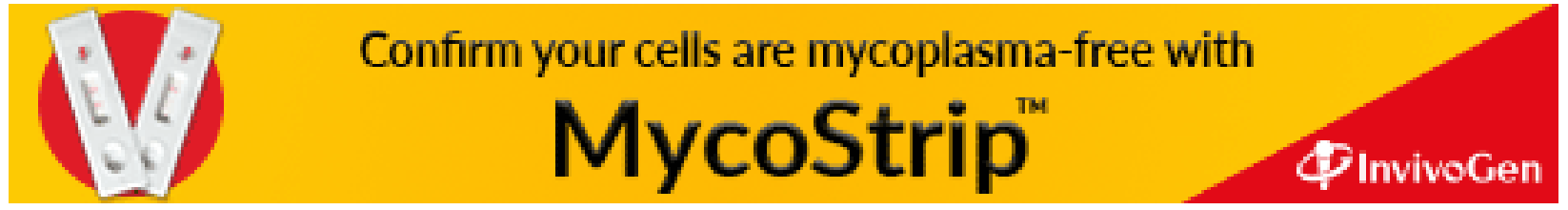

